\title{
LA SENTENCIA JUDICIAL COMO MEDIO DE PRUEBA**
}

\author{
THE VEREDICT AS EVIDENCE
}

\section{Alejandro Romero Seguel ${ }^{*}$}

\begin{abstract}
RESUMEN: Este trabajo explica la proyección probatoria que tiene una sentencia firme y ejecutoriada en el proceso civil chileno. Como acto procesal, la decisión judicial conforma una realidad jurídica y material que puede servir para acreditar un hecho en un proceso posterior, especialmente, en relación a la eficacia refleja de la sentencia, al efecto "ultra partes" de la misma y al valor que tiene un fallo en el sistema de producción de precedentes judiciales. Esta última manifestación se da cuando una decisión judicial sienta una doctrina sobre una materia o entra en contradicción con otras decisiones anteriores. En ambos casos se hará necesario acreditar ese hecho jurídico, con el objeto que la Corte Suprema unifique los criterios para que los tribunales resuelvan con la misma regla los casos análogos.
\end{abstract}

Palabras clave: jurisprudencia, unificación de jurisprudencia, discriminación judicial, igualdad ante la ley, prueba.

ABSTRACT: This study explains the possibilities of evidence that a final and enforceable verdict has on the Chilean civil process. As a proceeding, the court's decision constitutes a legal and material reality that can help to prove a fact in a subsequent lawsuit, particularly in relation to the reflex effect of the verdict to the meaning "ultra parties" of this desition and the value that a judicial sentence has in the production system of judicial precedents. This last statement takes place when a court's decision creates a doctrine on a particular subject or develop a contradiction with previous decisions. Both cases will require legal test of that fact, in order that the Supreme Court can unify the legal doctrine with the object that the courts can resolve with the same rule similar lawsuits.

Key words: precedent, precedents unification, judicial discrimination, nullity of a sentence, equality before the law, evidence.

\section{PRESENTACIÓN DEL TEMA}

Como acto procesal, la sentencia firme y ejecutoriada conforma una realidad jurídica y material que puede servir para acreditar un hecho en un proceso posterior, a lo menos en los siguientes sentidos:

(i) Cuando se alega la función negativa de la cosa juzgada. Como en nuestro sistema procesal esta excepción no puede ser apreciada de oficio por el juez, la parte que la alega debe acreditar su existencia, acompañando las sentencias donde ella consta ${ }^{1}$.

\footnotetext{
${ }^{* *}$ Este trabajo se realiza dentro del marco del proyecto Fondecyt Regular: "La generación de precedentes en el proceso chileno" (№ 1110917).

*Profesor de Derecho Procesal de la Universidad de los Andes.

Licenciado en Ciencias Jurídicas y Sociales, Universidad de Valparaíso; Doctor en Derecho, Universidad de Navarra; Director del programa de Doctorado en Derecho de la Universidad de los Andes.

${ }^{1}$ Así lo han resuelto, entre otras, Bauzá con Dirección (1939). Sobre el carácter formal del acto de alegación, la CS ha declarado, "... cabe señalar que las acciones como también las excepciones deben plantearse en el
} 
(ii) Cuando se hace valer la denominada eficacia positiva o prejudicial, para impedir que en un juicio posterior se decida una nueva acción en contradicción con la declaración del derecho que consta en un fallo que se encuentra firme y ejecutoriado, atendido que la decisión anterior actúa como un antecedente lógico a la nueva acción deducida en juicio.

(iii) Cuando la sentencia judicial es invocada por un acreedor como un título ejecutivo.

(iv) Cuando la sentencia contiene una condena genérica acerca de la existencia de un determinado ilícito civil, que permite a una de las partes o incluso a terceros, solicitar el derecho a ser indemnizado de los perjuicios en un nuevo juicio. En el caso de los terceros, como se explicará, se trata de ciertas hipótesis donde la eficacia de la sentencia hace excepción a la regla tradicional, en virtud de la cual se ha entendido que la cosa juzgada, al tercero, ni le perjudica ni le aprovecha ${ }^{2}$, al manifestarse la denominada eficacia refleja de la sentencia o, en su caso, el efecto "ultra partes" de la misma.

(v) Cuando por su contenido queda vinculada al mecanismo de producción de precedentes judiciales. Esta manifestación puede surgir porque el fallo sienta una doctrina sobre una materia o entra en contradicción con otras decisiones anteriores, al contener distintas interpretaciones sobre un determinado tema jurídico. En ambos casos se hará necesario acreditar ese hecho jurídico, con el objeto que la Corte Suprema proceda a unificar el criterio de decisión, con el objeto que los tribunales resuelvan con la misma regla los casos análogos.

Todas estas hipótesis donde se proyecta la sentencia judicial firme y ejecutoriada para un proceso posterior se explican dentro de la realidad que describe Taruffo, al señalar que "los medios de prueba son un fenómeno multifacético cuya naturaleza y definición varían de acuerdo con distintos factores históricos, culturales y jurídicos. Los sistemas probatorios han sufrido cambios profundos desde la época de los romanos; asimismo, las diferentes asunciones culturales acerca del conocimiento, la verdad y la función de las decisiones judiciales han tenido una fuerte influencia en las concepciones de la prueba. Y en este contexto, un factor adicional de complejidad y diferenciación es que son muchas las cosas que se pueden usar como fuentes de prueba. Según la interpretación dominante del principio de relevancia, cualquier cosa que tenga significado o cierta utilidad en la búsqueda de la verdad sobre los hechos litigiosos puede ser usada-al menos en principio- como un medio de prueba"3.

juicio y solicitarse un pronunciamiento del tribunal a su respecto y no procede que se deduzcan solo de los razonamientos que se contengan en los escritos presentados por las partes y como la excepción de cosa juzgada de que se trata no fue alegada formal y oportunamente en el juicio, como lo reconoce el propio demandante, no recayó pronunciamiento de los tribunales que han intervenido en el pleito, sobre tal materia, de manera que por tal motivo y por tratarse de una cuestión nueva, no discutida ni en primera ni en segunda instancia y que por lo tanto no puede ser promovida en el recurso de casación, corresponde el rechazo del recurso..." (Castro con Carretón (1981); Undurraga con Ugarte (1956).

${ }^{2} \mathrm{La}$ CS, ha resuelto en decenas de sentencias que el efecto de cosa juzgada no puede hacerse extensivo a personas que no tomaron parte en la relación procesal por no haber sido legalmente emplazadas: Macuada con Macuada (1939); Benacchio, Marcos, R. de Queja (1951); Banco del Estado con Lincir (1992).

${ }^{3}$ TARuffo (2008) p. 59. 


\section{SU ENCUADRAMIENTO COMO MEDIO DE PRUEBA}

La aceptación de la sentencia judicial como un medio de prueba está contemplada dentro de la regulación de los instrumentos ${ }^{4}$ o como una manifestación de la prueba de presunciones.

Como instrumento, ella puede ser aportada al proceso a instancia de parte o por iniciativa del juez ${ }^{5}$.

La relación de la sentencia judicial firme y ejecutoriada con la prueba de presunciones es una opción que fue influenciada por el Código Civil francés, de 1804. Dicho cuerpo legal vinculó la cosa juzgada con las presunciones de derecho (juris et de jure), excluyendo de toda otra prueba a lo declarado en un fallo judicial. Esta idea era una proyección de la doctrina de Pothier (1699-1772), y cuyas raíces se encuentra en el derecho común ${ }^{6}$.

En nuestra literatura jurídica, en la etapa anterior a la codificación, vinculaba el efecto de cosa juzgada a la prueba de presunciones el difundido Prontuario de los juicios, de José Bernardo Lira, publicado a fines del siglo XIX (1895). Allí se afirma que "la sentencia que causa ejecutoria tiene a su favor una presunción de verdad, contra la cual por razones de interés público no admite la ley pruebas de ninguna clase. De nada servirán, en efecto, las decisiones judiciales, si los litigantes conservan siempre la facultad de suscitar discusión sobre el acierto del fallo"7.

Aunque el Código Civil de don Andrés Bello no siguió en este punto literalmente al francés, nuestros autores clásicos, por influencia de la doctrina francesa, acogieron la explicación de la cosa juzgada como una presunción o una ficción de verdad ${ }^{8}$.

La codificación procesal chilena no estuvo ajena a esta idea, tal como consta de la historia fidedigna del establecimiento del artículo 159 de la Lei sobre Atribuciones y Orga-

${ }^{4}$ Meneses (2008) pp. 43-86.

${ }^{5} \mathrm{El}$ art. 178 del CPC dispone que "en los juicios civiles podrán hacerse valer las sentencias dictadas en un proceso criminal siempre que condenen al procesado. A su turno, el art. 273 No 3 del referido código, permite que se pueda solicitar como medida prejudicial la "exhibición de sentencias (...) u otros instrumentos públicos o privados que por su naturaleza puedan interesar a diversas personas". En relación a la prueba de oficio, el art. 159 del CPC admite que los tribunales, dentro del plazo para dictar sentencia, pueda decretar como medida para mejor resolver, "10 la agregación de cualquier documento que estimen necesario para esclarecer el derecho de los litigantes (...)”. También se podría conseguir el mismo objetivo a través del numeral 6, cuando señala que se podrá decretar como medida para mejor resolver, "la presentación de cualquiera otros autos que tengan relación con el pleito...”. En relación al valor que ella puede tener, la CS, ha declarado que, “(...) si bien los jueces del fondo ordenaron traer a la vista el expediente Rol (...), nada impide que su valor haya sido finalmente desestimado por existir otros elementos de prueba que sí lograron la convicción de los jueces. En otras palabras, no es improbable que el aporte de una medida para mejor resolver termine no siendo considerado frente a las otras probanzas que ya constaban en el proceso. Esto es, precisamente, lo que ha ocurrido en autos". Moya con Rojas (2010).

6 "Robert Joseph Pothier, último de los grandes juristas franceses anteriores a la Codificación, constituye el eslabón que une el Derecho histórico francés con la codificación revolucionaria. Su obra, que concilia, desde un planteamiento racionalista, el Derecho romano y el Droit coutumier, tuvo una influencia decisiva en la elaboración del Código civil francés (1804), que llega a incorporar literalmente en su articulado numerosos textos de Pothier" (Martínez de Aguirre (2004) p. 582). Sobre la cosa juzgada como una presunción, mayores antecedentes en Nieva Fenoll (2006) pp. 62-67.

${ }^{7}$ Lira (1895) p. 303.

${ }^{8}$ Claro (1921) p. 34, con expresa referencia a Pothier. 
nización de los Tribunales, de 1875 (actual 324 inc. 2o COT). Para justificar la inmunidad que tienen los magistrados de la Corte Suprema en ciertos delitos ministeriales, se arguyó, entre otras razones, que ello obedecía a la presunción de verdad que se atribuía a la cosa juzgada. Según los comisionados "toda sentencia de dicho tribunal se presumía de derecho verdadera, justa $\mathrm{i}$ en todo conforme a las disposiciones de la Lei”, y por ende, no era posible admitir que los ministros de nuestro máximo tribunal pudieran pronunciar fallos torcidos, incurriendo en los delitos de cohecho o en una prevaricación?

En el Código de Procedimiento Civil la vinculación de la sentencia firme y ejecutoriada a la prueba indiciaria se aprecia en el inciso final del artículo 429. Ahí se dispone que "igual presunción existirá a favor de los hechos declarados verdaderos en otro juicio entre las mismas partes".

Por último, la estrecha vinculación entre la cosa juzgada y la prueba ha sido recurrente en el tratamiento de ciertas hipótesis de prejudicialidad, que nuestra doctrina clásica denomina como las "influencia de la sentencia”, y cuya base legal está en los arts. 178, 179 y 180 del CPC.

\section{PECULIARIDADES DE LA SENTENCIA COMO INSTRUMENTO PÚBLICO}

La sentencia judicial es un instrumento público, si cumple con las exigencias del art. 1699 del CC., o cuando sus copias son consideradas como tales, según la enumeración de los que son considerados como tales en juicio conforme al art. 342 Nos. 2, 3, 4 y 5 del CPC.

No obstante lo anterior, en ella concurren algunos rasgos que la convierten en una prueba documental de singulares características, por las razones que pasamos a explicar ${ }^{10}$ :

a) El instrumento público se produce por la intervención de un ministro de fe investido por ley de la potestad para generarlo. Lo expresado en el documento público, en especial el de origen notarial, se tiene por verdadero respecto de los hechos que caen dentro de la esfera de percepción del ministro de fe, esto es, el hecho de haberse otorgado y su fecha (art. 1700 CC). En cambio, la sentencia judicial da cuenta del resultado final de la actividad jurisdiccional; el juez en este acto no actúa como ministro de fe. El carácter de instrumento público de la sentencia proviene de la intervención del secretario encargado de autorizar las resoluciones judiciales, cumpliendo con una exigencia esencial para la validez de esa actuación (arts. 379 No 2 COT y 61 inc. final del CPC). Sin embargo, la sentencia judicial no obliga por ser un instrumento público, sino que contener un mandato imperativo que proviene del órgano jurisdiccional.

b) La sentencia judicial no recoge una declaración de voluntad de las partes, en la forma como lo hace un acto o contrato suscrito ante un ministro de fe. Por el con-

\footnotetext{
${ }_{9}^{9}$ Esta idea de la infalibilidad de las sentencias de la CS ha sido ratificada en la jurisprudencial en los siguientes términos: "no es sostenible que en las resoluciones de la Corte Suprema pueda infringirse la ley y que, en consecuencia, llegue a producirse la denegación o torcida administración de justicia o que se alteren las reglas de procedimiento, por cuanto no existiría tribunal que pudiera resolver el posible error y establecer la verdad, de allí que se acepte como necesaria esa infalibilidad convencional de tales jueces y deban reputarse, en derecho, sus resoluciones conforme a la ley". Schweitzer. $R$ de Inaplicabilidad (1932).

${ }^{10}$ Para profundizar sobre este tema, Moreno (2001) pp. 17-57.
} 
trario, este acto procesal contiene una serie de enunciados fácticos y jurídicos que pronuncia un juez para decidir un conflicto con relevancia jurídica. La extensión y consistencia de este acto dependen de la forma como se cumpla con la garantía de la fundamentación de la sentencia.

c) La declaración del derecho materializada en la sentencia judicial no permite distinguir entre el efecto obligatorio y el acto jurídico, que nuestra jurisprudencia acepta en relación al alcance de las declaraciones contenidas en los instrumentos públicos. En tal sentido, se ha resuelto que una cosa es el efecto probatorio del instrumento público y otra, el efecto obligatorio del acto jurídico de que el instrumento cuenta ${ }^{11}$. En el caso de las decisiones judiciales, ellas obligan sin posibilidad de separar el mandato imperativo con el contenido obligacional que puede constar en una sentencia.

d) La sentencia judicial no está sometida al régimen de impugnación que nuestro sistema admite para declarar la nulidad de un instrumento público o de un contrato suscrito bajo esa formalidad o solemnidad. La escritura pública, una vez concluida no goza de la presunción de verdad que se atribuye a la cosa juzgada ${ }^{12}$. En cambio, una vez que un fallo queda firme y produce cosa juzgada material, el único medio para revertir su eficacia es la acción de revisión, siempre que esté fundada en alguna de las causales del art. 810 del $\mathrm{CPC}^{13}$. Si ello no acontece, la decisión no se puede modificar, salvo que la ley expresamente prevea un régimen especial ${ }^{14}$ o se haya configurado una hipótesis de cosa juzgada aparente, que pueda ser removida a través de algunos de los instrumentos que admite el ordenamiento jurídico ${ }^{15}$.

${ }^{11}$ Industrias con Impuestos Internos (1972).

12 Esto explica que lo declarado por una escritura pública pueda impugnarse por simulación, prescindiendo derechamente del valor probatorio de este instrumento, por ejemplo, porque el precio pactado en una compraventa es irrisorio. Aceituno con Aceituno (2010).

13 Excepcionalmente en algunos casos se ha establecido una reglamentación especial. Un ejemplo se contiene en la acción prevista para pedir la nulidad de la concesión minera (art. $95 \mathrm{CM}$ ).

${ }^{14}$ Un hito en este punto se encuentra en la sentencia pronunciada por la Corte Suprema en los autos Banco Hipotecario con Lagos (1924), al declarar que, "la acción ordinaria de nulidad que procede en nuestro derecho para pedir la nulidad de los actos y declaraciones de voluntad, que se gobierna por los preceptos de los arts. 1681, 1682 y 1683 del Código Civil no tiene aplicación actualmente, ni la tenía tampoco a la fecha de la dictación de la sentencia interlocutoria que dio lugar a la adjudicación, con respecto a las resoluciones judiciales, por cuanto, debiendo regirse las actuaciones procesales por las leyes especiales de enjuiciamiento, ninguna de las que se encontraban en vigor al dictarse la mencionada sentencia autorizaban el ejercicio de acción alguna encaminada a invalidar por medio de un juicio ordinario lo resuelto en otro juicio ya finiquitado" "Si bien las leyes de partidas, y entre ellas las leyes 1a, Tit. 26 de la Part. 3a y 28, Tit. 11 de la Part. 5a, que se invocan en el recurso, autorizaban originariamente el recurso que se llama de retractación, en señalados casos, esas leyes, restringidas en su alcance por las del Tít. 18 del Libro 11 de la Novisima Recopilación, fueron derogadas por la ley patria de $1^{\circ}$ de marzo de 1837 la cual, al conceder el recurso de nulidad por todos los motivos que enumera su art. 28 y además por cualquiera otro que produzca nulidad, según prevención expresa de las leyes, puso de manifiesto la voluntad del legislador de circunscribir al campo de acción de esa misma ley de nulidades todo lo que sobre la materia contenían las disposiciones hasta entonces vigentes y, consiguientemente, la voluntad de mantener, en lo demás, el principio de la presunción de verdad que entraña la cosa juzgada y que es base indispensable para la estabilidad de los derechos".

${ }^{15}$ La cosa juzgada aparente se produce cuando no ha existido algunos de los presupuestos procesales que actúan como requisitos de existencia. Se trata de casos de difícil ocurrencia, atendido que nuestro ordenamiento reconduce la mayor parte de las ineficacias jurídicas a la nulidad, y esta solo se puede alegar in limine litis. Concluido el proceso, la cosa juzgada subsanaría todos los vicios que pudieron ser materia de declaración de nulidad. Con 
A lo anterior se debe adicionar la improcedencia de la acción de nulidad de derecho público para impugnar resoluciones judiciales, atendido que el proceso jurisdiccional cuenta con un mecanismo exclusivo y excluyente de impugnación: el sistema de recursos procesales.

La doctrina anterior ha sido desarrollada en varias sentencias, resultando elocuente la decisión de la Corte Suprema, de 6 de mayo de 2002, al recordar en su considerando 170 lo resuelto en los autos rol 3.408-98, donde resolvió:

Sexto: que respecto del fallo ejecutoriado que ha puesto término a un procedimiento judicial, menos cabe entablar una acción de 'nulidad de derecho público', como la intentada en estos autos en la demanda de la actora y en cuya procedencia se insiste en el recurso de autos. La referida nulidad de derecho público se hace derivar básicamente del artículo $7^{\circ}$ de la Constitución Política, que previene que 'Los órganos del Estado actúan válidamente previa investidura regular de sus integrantes, dentro de su competencia y en la forma que prescriba la ley', que 'Ninguna magistratura, ninguna persona ni grupo de personas pueden atribuirse, ni aun a pretexto de circunstancias extraordinarias, otra autoridad o derechos que los que expresamente se les hayan conferido en virtud de la Constitución o las leyes' y que 'Todo acto en contravención a este artículo es nulo y originará las responsabilidades y sanciones que la ley señale”.

"Séptimo: Que si bien estas disposiciones, junto con otras normas del ordenamiento vigentes, enuncian el principio de legalidad a que debe someterse toda autoridad u órgano estatal y, ciertamente las que ejecutan la función jurisdiccional, las mismas no autorizan deducir una acción de nulidad en contra de una resolución judicial, en un procedimiento diverso de la causa en que ella se pronunció".

"Octavo: Que, en efecto, como se anotó en el considerando quinto, la anulación de los actos que llevan a cabo los tribunales en ejercicio de la potestad jurisdiccional del Estado, debe perseguirse a través de los medios que franquea la ley procesal y que, substancialmente, consisten en la declaración de nulidad de oficio o a petición de parte, que contemplan los artículos 83, 84 y 85 del Código de Procedimiento Civil, asi como en los recursos de casación y revisión que regulan, respectivamente, los Titulos XIX y XX del Libro III del mismo texto y las normas pertinentes del Código de Enjuiciamiento Penal, o bien, excepcionalmente, por medio del ejercicio de las facultades disciplinarias de los Tribunales Superiores, conforme en el artículo 545 del Código Orgánico de Tribunales"16.

todo, nuestra jurisprudencia ha constatado hipótesis de cosa juzgada aparente, surgidas del hecho de haberse demandado y condenado a un Estado extranjero en Chile. Ello consta en Marchant con Gobierno (1969) y "Senerman con República de Cuba" (1975). Sobre este tema, cfr. las ponencias del XVIII Jornadas Iberoamericanas de Derecho Procesal, Montevideo, FCU, 2002, pp. 391-604.

16 Sociedad Contractual Minera Carola con Sociedad Punta del Cobre S.A. (2002). Con anterioridad había sentado el mismo criterio la sentencia de la Corte, pronunciada en Municipalidad con Espinoza (2000), al señalar: "Decimocuarto: Que, en este sentido, es pertinente citar lo expuesto en el Mensaje con el que el Presidente de la República remitió al Congreso Nacional el proyecto del Código de Procedimiento Civil con fecha $1^{\circ}$ de febrero de 1893: 'Terminan los procedimientos especiales con el que debe servir para el recurso de casación en la forma y en el fondo. No difiere el primero sustancialmente del actual recurso de nulidad, pero se ha procurado llenar los vacios del actual y aclarar las dudas que en él se notan. Se determinan los trámites cuya omisión da lugar al recurso, y se desconoce de un modo expreso la acción ordinaria de nulidad para invalidar sentencias, no admitiéndose otro camino 


\section{LA SENTENCIA JUDICIAL COMO UNA PRESUNCIÓN}

Como se anticipaba, la sentencia judicial ha sido vinculada a la prueba de presunciones por la influencia del Código Civil francés, que aceptó en esta materia la doctrina de Pothier sobre la cosa juzgada como una "presunción de verdad". La fuente remota de esta tesis estaría en la regla de Ulpiano, contenida en el Digesto (D. 1.5.25), al señalar que la cosa juzgada se tiene por verdadera (res judicata pro veritate habetur).

En nuestro derecho positivo, esta opción se contempla en el art. 427 inc $2^{\circ}$ del CPC, propuesta que admite varias observaciones criticas.

En primer lugar, tal como consta en las actas de la Comisión Mixta de Senadores y Diputados, en la sesión 22, de 19 de noviembre de 1901, al debatirse este precepto (que corresponde al actual art. 427 del CPC), el comisionado Vergara solicitó que se debía precisar "lo que se entiende por hechos declarados verdaderos en otro juicio". "El señor Presidente contesta que esta disposición solo puede referirse a hechos que ha declarado verdaderos una sentencia dictada en un juicio sobre materia diversa o entre partes distintas, porque

que el de la casación para lograr este resultado; en obsequio a la brevedad de los procedimientos y al tranquilo goce de los derechos declarados en juicio'. Estas observaciones recogieron las opiniones vertidas por diversos integrantes de la Primera Comisión Revisora del mismo proyecto del Código, en orden a que este no admitiría la acción ordinaria de nulidad contra las sentencias. Decimoquinto: Que sobre la base de estos antecedentes, don Victor Santa Cruz Serrano formuló en su estudio de Las nulidades procesales en el Código de Procedimiento Civil Chileno (Santiago, 1942, pág. 25), dos reglas generales en torno a la anulación de los actos jurisdiccionales, que conservan por completo su autoridad en el régimen vigente: 'a) La nulidad de los actos procesales solo puede obtenerse dentro del mismo juicio en que ellos inciden por medios o recursos procesales. No son procedentes, en consecuencia, las acciones ordinarias de nulidad absoluta o relativa que concede el Código Civil para obtener la invalidación de actos o contratos civiles' y 'b) Los medios o recursos procesales que la ley concede para invalidar actuaciones en un juicio solo proceden in lamine litis, esto es, mientras está pendiente el juicio a que se refieren y antes que su sentencia definitiva haya pasado en autoridad de cosa juzgada. Decimosexto: Que aun cuando estas observaciones versaron sobre la imposibilidad de deducir una acción de nulidad civil respecto de una sentencia u otro acto judicial en un juicio distinto de aquél en que fueron emitidas, ellas son igualmente aplicables en el campo de la nulidad de derecho público, especialmente si se tiene presente lo expresado anteriormente, en cuanto a que no existe otra forma de invocar esta última clase de nulidad que la de iniciar un juicio ordinario sujeto a las reglas del Derecho Procesal Civil. Decimoséptimo: Que la idea que la nulidad de Derecho Público no alcanza a las sentencias y otros actos jurisdiccionales, fue planteada, junto con delinearse esa teoría, por el constitucionalista don Mario Berna China, al exponerla en su trabajo pionero sobre las 'Bases Jurisprudenciales para una teoría de las nulidades administrativas' (Boletín del Seminario de Derecho Público de las Escuelas de Ciencias Juridicas y Sociales de la Universidad de Chile, Nos 45-48 de 1949, págs. 551 y siguientes), señalando que 'A pesar de que los tribunales de justicia crean actos estatales y de que sus resoluciones son imputables al Estado mismo, por ser órganos de este, no cabe aplicar las reglas de las nulidades de Derecho Público a las decisiones de los tribunales, porque se opondrían al imperio y a la independencia total de que se ha querido revestir a la judicatura por las normas positivas. En efecto, existen reglas especiales que han dado origen a una nulidad también especial, la llamada nulidad procesal que impide aplicarle las reglas que hemos deducido del artículo 4o, 23 y 75 de la Constitución Política (de 1925). Por su parte, el Código Orgánico de Tribunales establece una tramitación para la nulidad procesal que la equipara a las nulidades civiles'. El mismo predicamento asumió Eduardo Jara Miranda en su estudio sobre Nulidad de Derecho Público (Editorial Universitaria, 1950, pág. 38), desechando la aplicación de la nulidad de Derecho Público a las decisiones de los Tribunales de Justicia de acuerdo con razones semejantes. Decimoctavo: Que el criterio de desestimar la posibilidad de extender la nulidad de derecho público al ámbito jurisdiccional y de reconocer que en este solo pueden tener cabida las nulidades procesales, es congruente con la naturaleza propia de la función judicial y las características de las actuaciones que se llevan a cabo en su ejercicio y que hace que la institución de las nulidades procesales tenga una fisonomia propia y singular en el amplio campo de la teoría de nulidad de las actuaciones de los órganos estatales, que sanciona la infracción de las normas constitucionales conducentes al cabal cumplimiento del principio de legalidad que deben observar dichos organismos". 
de otra manera no se alegaría la presunción sino la cosa juzgada”. Para el comisionado Ballesteros, "este segundo inciso estaría tal vez mejor colocado en la parte del Proyecto que trata de los efectos de la sentencia”. En la sesión siguiente, lamentablemente no se continuó con esta discusión del tema, legándonos una norma ambigua y de difícil aplicación ${ }^{17}$.

En segundo lugar, la escueta declaración del inc. $2^{\circ}$ del art. 427 del $\mathrm{CPC}^{18}$ no clarifica qué tipo de presunción sería la que surge de la sentencia judicial firme. Tal omisión tampoco se resuelve con la definición del 47 del CC, cuando dispone que "se dice presumirse el hecho que se deduce de ciertos antecedentes o circunstancias conocidas". "Si estos antecedentes o circunstancias que dan motivo a la presunción son determinados por la ley, la presunción se llama legal". Luego, el mismo precepto dispone que "si una cosa, según la expresión de la ley, se presume de derecho, se entiende que es inadmisible la prueba contraria, supuestos los antecedentes o circunstancias".

Es un hecho conocido que la doctrina científica ha criticado la vinculación de la cosa juzgada con la prueba de presunciones. De un modo particular, Carreras Llansana sostiene que la configuración de la cosa juzgada como una presunción -y por tanto como un medio de prueba- no puede ser más desafortunada; según este autor, la cosa juzgada no es una presunción y su calificación legal trae origen en una confusión antigua entre presunciones y ficciones jurídicas ${ }^{19}$.

En el caso de la sentencia judicial, por su estructura y contenido no puede seguir la técnica de las presunciones legales, atendido que la realidad fáctica que ella comprende no está determinada con antelación. En la presunción de derecho o en la simplemente legal, es el legislador, según el caso, quien libera de prueba o da por sentado de qué hechos es posible extraer una determinada conclusión ${ }^{20}$. Como lo describe Devis Echandía, "en el razonamiento del juez que aplica una presunción legal, se parte de la regla general contenida en la norma, que indica lo ordinario en una especie de fenómenos materiales o morales y que constituye la premisa mayor (por ejemplo: el hijo de mujer casada puede tener por padre al marido); se aplica luego esa norma o la máxima de experiencia contenida en ella, al hecho probado que se considera idéntico o análogo al que sirve de presupuesto de aquella, que constituye la premisa menor (el es un hijo de la mujer casada); la conclusión es la consecuencia deductiva de aplicar aquella regla general a ese caso concreto análogo o idéntico (luego este es hijo del marido de la madre)"21.

\footnotetext{
${ }^{17}$ Sobre esta discusión cfr. sesiones de 28 de abril de 1871 y 13 de mayo de 1873 , citadas por Ballesteros (1890) pp. 7-9.

${ }^{18}$ Sobre el alcance de esta norma se ha fallado, “...que de conformidad a lo que dispone el artículo 427 del Código de Procedimiento Civil, se presumen verdaderos los hechos declarados tales en otro juicio diverso entre las mismas partes. Para tal efecto se exige entonces que el otro juicio haya sido ventilado entre las mismas partes, pues de otro modo no habría existido la necesaria contradicción y que sobre los hechos en cuestión haya recaído un pronunciamiento judicial por el que se declaren verdaderos". Vásquez con Vásquez (1965).

${ }^{19}$ Carreras (1962) p. 339. Otros antecedentes en Martínez de Morentín (2007) pp. 103-124.

${ }^{20}$ Por ejemplo, se presume de derecho "que la concepción ha precedido al nacimiento no menos que ciento ochenta días cabales, y no más que trescientos, contados hacia atrás, es de la medianoche en que principie el día del nacimiento" (art. 76 inc. $2^{\circ} \mathrm{CC}$ ); presume muerto el individuo que ha desaparecido, ignorándose si vive y verificándose las condiciones que van a expresarse..." (art. 80 CC).

${ }^{21}$ Devis Echandía (2002) p. 609.
} 
No obstante lo anterior, no se puede desconocer que entre sentencia judicial y la prueba de presunciones podría darse una vinculación en la declaración contenida en la parte resolutiva, y también en los que la doctrina y jurisprudencia denominan como "considerandos resolutivos", "objetivos" o "decisorios" 22 . En ese lugar podría contenerse alguna declaración que sirva para acreditar un hecho en un juicio posterior, sin perjuicio de la función natural que esa parte del fallo tiene en la determinación de la identidad objetiva de la cosa juzgada.

Con todo, lo anterior no es fácil de concretar, atendido que uno de los temas más complejos de resolver en relación a los límites objetivos de la cosa juzgada, es fijar qué elementos configuran la causa de pedir de la acción que ya fue fallada: si solo un conjunto de hechos; o si junto a los hechos, debe considerarse también al elemento jurídico fundante de la acción.

Dicho de otra forma, el encasillamiento de la sentencia judicial dentro de las presunciones no soluciona automáticamente qué parte del fallo judicial firme y ejecutoriado puede ser proyectado con eficacia probatoria para un proceso ulterior. Como lo explica Tapia Fernández, "históricamente se ha admitido sin discusión que la cosa juzgada cubre no solo lo efectivamente deducido en el primer proceso, sino también lo que pudo deducirse". Luego, agrega la misma autora, que "esta máxima refleja la lógica consecuencia de la naturaleza jurídica de la cosa juzgada como concreta determinación de las recíprocas situaciones jurídicas de las partes en contienda, y no como una mera operación cognoscitiva sobre los argumentos o razones o sobre el valor persuasivo o no de las pruebas; de tal modo que, establecida en la sentencia la concreta relación jurídica entre las partes, es irrelevante que a tal resultado se haya llegado acogiendo o rechazando tal argumentación o tal prueba. Todas las razones que se alegaron o se pudieron alegar quedan cubiertas por la cosa juzgada"23.

\section{SU CALIFICACIÓN COMO FICCIÓN LEGAL}

Frente a la dificultad que tiene explicar la cosa juzgada como una manifestación de las presunciones, parte de la doctrina ha postulado que esta declaración del derecho está más cerca de las ficciones, que de la prueba indiciaria. Como lo puntualiza Gascón, en la medida en que las normas que establecen la presunción no permiten destruir esta mediante prueba en contrario, tales presunciones han sido asimiladas a las ficciones ${ }^{24}$.

En palabras de Devis Echandía, "la ficción, a diferencia de la presunciones, solo puede ser obra del legislador y consiste en suponer existente o inexistente un hecho o una cosa que no es así, o en trasladar las consecuencias jurídicas de un estado de cosas a otro diferente, como si fuesen iguales". "Hay de común entre ficción y las presunciones iuris et de iuri que no admiten prueba en contrario" 25 .

\footnotetext{
${ }^{22}$ En nuestra doctrina, Tavolari ha delimitado este concepto señalando que "para calificar un razonamiento de considerando resolutivo, debe atenerse a varias exigencias: a) Formalmente, debe ubicarse entre las motivaciones del fallo. Su presencia en la parte resolutiva excluiría, en principio, el debate y conduciría a calificar la oración como decisión. b) Sustancialmente, debe importar un anticipo efectivo de la decisión que, por tal puede o no reiterarse, en lo resolutivo. c) Puede contener el establecimiento de los hechos del pleito o, a lo menos, de aquellos cuya existencia representan el fundamento inmediato de la sentencia”. TAvolari (2000) p. 216.

${ }^{23}$ TAPIA (2000) pp. 155-156, (2010 b) pp. 107-185.

${ }^{24}$ Gascón (2004) p. 147.

25 Devis Echandía (2002) p. 691.
} 
En un estudio sobre las ficciones, Mendoça explica que, “(...) la diferencia entre presunciones y ficciones radicaría, principalmente, en la función que desempeñan en el derecho unas y otras, sobre todo en el marco del razonamiento judicial. Las ficciones son, en lo sustancial, como ya se ha dicho, un mecanismo de asimilación a los efectos de la remisión de soluciones, mientras que las presunciones son un mecanismo de superación de situaciones de incertidumbre, en razón de la ausencia de elementos de prueba a favor o en contra de determinada proposición, proposición que resulta relevante para resolver el caso sometido a decisión judicial. De este modo, la incorporación de presunciones por vía legal constituye un mecanismo del cual se vale el derecho para resolver, en un sentido determinado, aquellos casos en que existe incertidumbre acerca de si se han producido ciertas circunstancias de hecho, correlacionadas con ciertas soluciones por normas del sistema en cuestión"26.

En síntesis de Gascón: las ficciones legales han sido presentadas tradicionalmente como el artificio jurídico más alejado de la verdad, el triunfo definitivo de la simulación y el engaño sobre la realidad: "un hecho notoriamente falso sobre el cual se razona como si fuera verdadero" (J, Betham), "una mentira técnica" (R. von Ihering), "una mentira convencional" que, sin embargo, tienen más fuerza que la "verdad verdadera", pues ella "no ha menester rodearse de pruebas" (A. Bonilla); y en fin, un procedimiento oblicuo de construcción jurídica mediante la cual "se da por existente lo que no ocurrió, o se da por no sucedido lo que aconteciera ${ }^{27}$.

Ahora, la consideración de la cosa juzgada dentro de las ficciones llevaría a estimar como verdadero un determinado hecho, aunque no lo sea en realidad. Esta propuesta cuenta en nuestra jurisprudencia con algunos pronunciamientos que han reconocido, por ejemplo, que "el principal efecto de una sentencia ejecutoriada es que los litigantes y sus herederos quedan obligados a su cumplimiento y a estar y pasar por ella. Cualesquiera sean los errores de que adolezca, debe tenérsela por expresión de la verdad sobre la materia que se traduce en la acción y excepción de cosa juzgada" ${ }^{28}$. En la misma orientación, se ha sostenido que "los efectos esenciales de la cosa juzgada que produce una sentencia definitiva ejecutoriada, consisten precisamente en que la decisión adoptada pone fin definitivamente al litigio como expresión representativa de la verdad..."29.

\section{ALGUNOS LÍMITES PARA LA UTILIZACIÓN DE LA SENTENCIA COMO MEDIO DE PRUEBA}

Cualquiera que sea la calificación que se atribuya a la declaración contenida en una sentencia judicial firme y ejecutoriada (como presunción o como ficción), su valor probato-

\footnotetext{
${ }^{26}$ Con referencia a otros autores y a sus propios estudios, Mendoça (2003) pp. 16-17.

${ }^{27}$ Gascón (1994) p. 147.

${ }^{28}$ Anrique con Monasterio (1921). En la misma orientación Zañartu con Higueras (1937), al señalar la existencia de un principio universal: res judicata pro veritate habetur, como corolario natural de toda sentencia judicial. En igual sentido, Banco con Lagos (1924), aludiendo al "principio de presunción de verdad".

${ }^{29}$ Phillips con Baeza (1994).
} 
rio en un juicio ulterior no puede dejar de considerar una serie de limitaciones que provienen del acto procesal de prueba ${ }^{30}$.

Sin perjuicio de otras barreras, la primera es definir en cuál de las tres formas que tiene un juez para lograr la convicción probatoria se encuentra un fallo firme y ejecutoriado.

Como se sabe, para dar por acreditado un hecho controvertido el juez puede establecer la verdad judicial a través de alguna de las siguientes formas: 10) Comprobando por sí mismo el hecho material, a partir del tenor de un documento o de una percepción directa. $2^{\circ}$ ) Remitiéndose el juzgador a la declaración de un tercero o de la parte (un testigo o un perito, o la confesión judicial o extrajudicial). $3^{\circ}$ ) Llegando el juzgador a la verdad mediante un razonamiento, al deducir de hechos conocidos los hechos desconocidos o discutidos (prueba de presunciones o indiciaria).

Para lo que aquí nos interesa, por la naturaleza que tiene la sentencia firme y ejecutoriada, ella puede participar en la $1^{\text {a }}$ o en la $3^{\text {a }}$ categoría. En efecto, será un medio de percepción directa si el fallo se hace valer ante el mismo juez que pronunció la causa, invocando el efecto que la declaración del derecho puede tener para un proceso ulterior.

También podría ser utilizada como un medio de prueba para construir una presunción judicial, en cuanto la sentencia contenga el hecho conocido del que es posible extraer una conclusión probatoria, siguiendo en ello el procedimiento que reconoce la Corte Suprema para tal efecto: “(...) para establecer una presunción judicial se requiere la existencia de un hecho real y debidamente probado que sirve de base para deducirla; un hecho desconocido cuya existencia se pretende averiguar y una relación que es la que determina el juez mediante estos razonamientos" 31 .

Por otro lado, otra limitación natural de una sentencia judicial firme y ejecutoriada, para ser utilizada como medio de prueba, surge de la distinción entre la cosa juzgada material y la cosa juzgada formal. La diferencia entre ambos conceptos es radical, y tiene una repercusión directa en el mérito que se quiera atribuir a una decisión judicial para un juicio posterior.

La cosa juzgada material alude al litigio examinado en el juicio y resuelto por una sentencia que alcanza inmutabilidad. Es la certeza más absoluta que obtiene una decisión jurisdiccional, sea que haya acogido o rechazado la acción deducida en un juicio. La cosa juzgada material es la decisión jurisdiccional inmutable e irrevisable en un juicio posterior.

En cambio, bajo la expresión cosa juzgada formal, se alude a las decisiones judiciales -también sentencias definitivas e interlocutorias- que son susceptibles de una revisión posterior. Las resoluciones judiciales con valor de cosa juzgada formal se generan en ciertas situaciones de excepción, en las que por razones de justicia o de economía procesal se permite examinar nuevamente el tema ya decidido, iniciando un nuevo juicio. En estos casos, la sentencia judicial, no obstante haber alcanzado el grado de resolución firme o ejecutoriada (según las posibilidades del art. 174 del CPC), e incluso siendo posible su ejecución o

\footnotetext{
${ }^{30}$ Sobre el tema, Picó I Junoy (1996) pp. 39-61; Comoglio (2004) pp. 13-69.

${ }^{31}$ O'Ryan con Ruiz Tagle (1970).
} 
cumplimiento judicial, por razones de política legislativa no adquiere la inmutabilidad (que es algo propio de la cosa juzgada material) ${ }^{32}$.

Para lo que aquí interesa, la sentencia amparada por la cosa juzgada formal no puede ser considerada como un elemento de convicción, atendido que la declaración del derecho en ella contenida es esencialmente revocable. Solo los fallos amparados por la cosa juzgada material gozan de la inmutabilidad que permite su utilización en algunas de las proyecciones probatoria que tiene la sentencia judicial.

\section{LA SENTENCIA JUDICIAL COMO UN HECHO JURÍDICO}

Un tema relevante y de difícil solución es el valor probatorio que se puede atribuir a la sentencia respecto de terceros.

Para tratar de resolver los múltiples problemas que esta situación provoca, la doctrina procesal ha venido proponiendo que la sentencia judicial sea considerada como un hecho jurídico.

Aunque esta temática tiene un alcance teórico que supera el marco de este trabajo, lo básico en esta descripción es recordar las palabras de Liebman, cuando puntualizaba en su conocido trabajo Eficacia y autoridad de la sentencia, que la concepción clásica de la cosa juzgada duró hasta el día "en que se hizo el análisis del contenido y de los efectos de la sentencia, descubriéndose que los mismos pueden ser de índole muy diversa según los casos"33.

En palabras de Carpi, la tendencia de la doctrina a extender la eficacia de la sentencia a los terceros responde a una concepción del derecho, y el particular del proceso, no más restringidas a individualismos decimonónicos, sino consciente del innegable dato social, de la complejidad e intercomunicabilidad de las relaciones, en último análisis, de la publicización más acentuada del proceso, espejo de un momento histórico y de sus ideologías ${ }^{34}$.

El origen de este tema se encuentra en un trabajo publicado en 1871 por Rudolf von Ihering, quien examinó las consecuencias que, en la realidad, puede producir la suscripción de diversos actos jurídicos. El planteamiento anterior fue tomado para el derecho procesal por Adolf Wach (1843-1926), distinguiendo tres categorías de posibles efectos que una sentencia puede generar: los de condena, los constitutivos y los declarativos ${ }^{35}$.

\footnotetext{
${ }^{32}$ Esta distinción doctrinal la explica claramente la sentencia Japaz con Balbontín (1980), al declarar: "se entiende por cosa juzgada formal el efecto que produce una sentencia definitiva o interlocutoria firme, en cuanto no puede ser objeto de recurso alguno, pero admite la posibilidad de modificarse lo resuelto en un procedimiento posterior. La sentencia es inimpugnable por recurso alguno, pero es mutable mediante sentencia dictada en un juicio diverso. En cambio, la cosa juzgada material o substancial, es el efecto que produce una sentencia firme, definitiva o interlocutoria, en cuanto no puede ser objeto de recurso alguno, ni de modificación en el mismo juicio ni en un procedimiento diverso".

${ }^{33}$ Liebman (1946) p. 22. A este autor se le debe la distinción entre cosa juzgada y eficacia de la sentencia. A partir de este aporte se hizo general la aceptación de que los efectos reflejos derivaban de la sentencia y no de la cosa juzgada. Para Liebman la cosa juzgada no es un efecto de la sentencia, sino una cualidad de inmutabilidad de los efectos de la sentencia (declarativos, constitutivos y de condena). La sentencia, conforme a esta doctrina, tendría una eficacia general, que deriva de su naturaleza de acto de autoridad proveniente de un órgano del Estado.

${ }^{34}$ Carpi (2007) p. 40.

35 WACH (1977) p. 32. A la propuesta anterior le sobrevendrían otras explicaciones de la doctrina alemana (Kuttner, Hellwig, Goldschmidt, Kisch, Schönke, Rosenberg, etc). En Italia el tema sería introducido por
} 
En lo concreto, la sentencia firme y ejecutoriada puede producir efectos respecto de cierto tipo de terceros, que sin haber sido parte del proceso, por tener respecto del objeto allí decidido una determinada posición jurídica terminan siendo vinculados con la declaración contenida en una sentencia firme y ejecutoriada. Como lo explica Grande, "no todos los terceros se hallan en la misma situación frente al proceso seguido inter alios, sino que, en función de la conexión existente entre su situación jurídica y la deducida por las partes en el proceso, la decisión que en este se adopte puede repercutir de modo más o menos intenso en aquella, lo que permite encuadrarlos en distintas categorías" 36 .

Como lo sintetiza Rosende, "la sentencia puede ser contemplada desde dos puntos de vista: como acto y como hecho jurídico". "Con la expresión sentencia como acto nos referimos a la declaración de voluntad del juez sobre el objeto sometido a su decisión una vez alcanzada una decisión sobre el mismo. Al resolver la controversia jurídica, del pronunciamiento del juez se derivan una serie de efectos queridos y previstos por el mismo en la resolución y perseguidos por las partes al promover el proceso. Son los efectos directos, esto es, los constitutivos, declarativos o de condena, dependiendo de la pretensión ejercitada, así como el efecto de cosa juzgada". "De otro lado, la sentencia se puede considerar también como hecho jurídico. Se alude con este concepto, al mismo fenómeno contemplado desde una perspectiva diversa: como acaecimiento desligado de la voluntad del juzgador. Por la mera existencia de un pronunciamiento judicial se constatan determinados efectos no queridos ni previstos por el juez en la resolución, ni perseguidos directamente por las partes al promover el proceso. Son los efectos indirectos, colaterales, secundarios o reflejos, cuando van referidos a los terceros. Puesto que no se pueden atribuir directamente a la declaración de voluntad en que consiste la sentencia, pues están fuera del objeto de la misma, su causa inmediata debe hallarse en una circunstancia diversa, esto es, en la ley o en la conexión de las situaciones jurídicas. La sentencia, como hecho jurídico, se integra en el supuesto de hecho de normas de las que se derivan efectos -colaterales o reflejos- con un contenido determinado y diverso en cada caso" 37 .

Para el tema que nos ocupa, la contemplación de la sentencia como un hecho jurídico pone énfasis en la inmutabilidad y la certeza jurídica que con ella se obtiene, concibiéndola como una realidad de variadas y múltiples proyecciones ${ }^{38}$. Como bien lo describe

Chiovenda en sus Principios de Derecho Procesal Civil, en relación a la eficacia de la cosa juzgada para terceros. Luego vendría una proliferación de aportaciones en los trabajos de Allorio, Liebman, Carnelutti, Costa, Redenti, Calamandrei, Trocker, Balena, entre otros.

36 Grande (2008) p. 27.

37 Rosende (2001) pp. 493-494. En similar orientación, Grande señala que "tales efectos, que normalmente se caracterizan por su involuntariedad, se producen cuando existe conexión y dependencia entre las distintas relaciones o situaciones jurídicas, y se concretan en que los efectos jurídico-materiales directos (declarativos, de condena o constitutivos) derivados de la sentencia que decide sobre la relación prejudicial integran, total o parcialmente, el supuesto de hecho de la norma que rige la relación dependiente, que los toma como hechos constitutivos, modificativos o extintivos de esta, y extrae de ellos ciertas consecuencias jurídicas para los titulares de la relación o situación jurídica dependiente que es objeto de regulación” (Grande (2008) p. 26).

${ }^{38}$ En nuestra jurisprudencia se aprecia un intento por utilizar estas categorías en el voto de un Ministro de la Corte de Apelaciones de Santiago, que no concurrió a declarar el desafuero de un político teniendo también en cuenta, "que en el caso sub judice, se declara la imposibilidad de proseguir esta acción de carácter penal (...) en virtud de la eficacia refleja del fallo ejecutoriado de la Corte Suprema, al que lo precedió un sumario en el que se reunieron todas las pruebas sobre el tema de la salud mental actual de aquel, evitándose asi un eventual conflicto entre ambas 
Calamandrei, "la cosa juzgada no crea ni una presunción ni una ficción de verdad: la cosa juzgada solo crea la irrevocabilidad jurídica del mandato, sin cuidarse de distinguir si las premisas psicológicas de las cuales ese mandato ha nacido son premisas de verdad o solamente de verosimilitud ${ }^{39}$.

\section{ALGUNAS SENTENCIAS QUE ACTÚAN COMO UN HECHO JURÍDICO}

Nuestro derecho positivo no es ajeno a la temática de la sentencia cuya eficacia es invocada en un proceso ulterior por terceros. Según el caso, estos pueden invocar la eficacia refleja o el efecto "ultra partes" de la sentencia civil. Como se explicará, se trata de hipótesis incorporadas por el legislador o que se coligen por la existencia de relaciones jurídicamente dependientes o conexas, que reclaman este tratamiento jurídico.

En definición de Carpi, "los efectos reflejos consisten en la transmisión a los terceros de la cosa juzgada y no son queridos por la ley ni previstos por el juez; ellos se verifican como consecuencia de una concomitante situación de derecho sustancial, en el sentido de que la sentencia influye sobre la relación jurídica del tercero, a través de la regulación dada a la relación entre las partes" 40 .

Por su lado, la eficacia "ultra partes", como se verá, se vincula a situaciones jurídicas donde hay varios sujetos legitimados o colegitimados, y cuya actuación puede producir una sentencia judicial cuyos efectos se extiendan a terceros que se encuentran en su misma posición.

\subsection{EN MATERIA DE LIBRE COMPETENCIA}

La protección de la libre competencia cuenta con un proceso civil especial, regulado en el DL 211 de 1973 (modificado por la Ley No 20.361 de 13 de julio de 2009). En él, el Fiscal Nacional Económico tiene legitimación para actuar en la defensa del interés general de la colectividad, ello sin perjuicio de las acciones que puedan deducir los particulares por el mismo tema ${ }^{41}$.

decisiones y no como un efecto directo de cosa juzgada de dicha sentencia". "Que si la eficacia refleja de la sentencia alude en cuanto al proceso civil "a los efectos que un fallo judicial no pretende producir directamente" en otro procedimiento distinto, "ino que derivan de la dictación de una sentencia, en cuanto se comporta como hecho jurídico material" y, además, "los efectos reflejos se explican, en la mayoría de los casos, por la vinculación que puedan presentar las relaciones jurídicas materiales, razón por la cual cuando una sentencia condena, declara o constituye, puede influir también sobre relaciones jurídicas conexas a las que fueron materia de la decisión" (La Cosa Juzgada en el Proceso Civil Chileno, (...) página 104), tal significado no es extraño al procesal penal que permite al tribunal pronunciarse sobre todos los actos jurisdiccionales que demande el desarrollo de la acción penal, entre estos, la consecuencia de la eficacia refleja de una sentencia, en este caso, en cuanto el sobreseimiento definitivo es "dicti ius" al decir algo incontrovertible respecto de una persona determinada". " Por lo que si la eficacia refleja resulta aplicable a la competencia por conexidad (R.D.J. Tomo LXXV, segunda parte, sección cuarta, página 276), que evita que se pronuncien fallos incongruentes o contradictorios, lo que ocurriría de seguirse por separado la investigación de cada una de las infracciones cometidas por el delincuente, nada impide que tal enlazado resulte atinente en la especie, en virtud del principio de la aplicación unitaria de la ley penal, atento siempre al conocimiento integro de los hechos investigados, al examen conjunto de las pruebas y al mejor conocimiento de la persona del imputado (Desafuero de Augusto Pinochet (2002)).

${ }^{39}$ Calamandrei (1986) p. 321.

${ }^{40}$ CARpi (2007) p. 61.

${ }^{41}$ El requerimiento es el nombre técnico que recibe el escrito que contiene la acción ejercida por el FNE para la 
Por su parte, el Tribunal de Defensa de la Libre Competencia debe resolver el asunto contencioso materia del proceso, absolviendo o condenando al sujeto pasivo a quien se imputa alguna conducta que califique como un ilícito que afecte el regular funcionamiento del mercado.

Ahora, en el evento que allí se pronuncie una sentencia de condena, esta puede ordenar la corrección, prohibición o represión de conductas anticompetitivas debidamente acreditadas en la causa y también la adopción de medidas preventivas, junto con la aplicación de una multa (art. 1 y 26 del DL 211).

Como el Tribunal de Defensa de la Libre Competencia no tiene la facultad legal para pronunciarse sobre acciones indemnizatorias, la ley ha previsto un ulterior proceso en el que puede surgir una hipótesis de eficacia refleja de la sentencia. Para lo que aquí interesa, el art. 30 del DL No 211 dispone: "la acción de perjuicios a que haya lugar, con motivo de la dictación por el Tribunal de Defensa de la Libre Competencia de una sentencia definitiva ejecutoriada, se interpondrá ante el tribunal civil competente de conformidad a las reglas generales, y se tramitará de acuerdo al procedimiento sumario, establecido en el Libro III del Título XI del Código de Procedimiento Civil” 42 .

"El tribunal civil competente, al resolver sobre la indemnización de perjuicios, fundará su fallo en las conductas, hechos y calificación jurídica de los mismos, establecidos en la sentencia del Tribunal de Defensa de la Libre Competencia, dictada con motivo de la aplicación de la presente ley".

La declaración de ilicitud contenida en este fallo permite que tanto la parte vencedora como un tercero que no actuó en esa relación procesal, puedan invocar en su beneficio la condena, dando por sentada en su acción civil la ilicitud de "las conductas, hechos y calificación jurídica de los mismos.

En relación a la parte vencedora en el proceso de libre competencia, la utilización de la sentencia en el juicio posterior es una proyección de la denominada eficacia positiva o prejudicial de la cosa juzgada. En efecto, el fallo contiene una declaración del derecho que actúa como un antecedente lógico para decidir la nueva acción deducida en juicio, en términos de dar por acreditada la ilicitud de la conducta del demandado.

defensa del “interés general”. También puede ser iniciado mediante una demanda presentada por algún particular, la que deberá ser puesta en inmediato conocimiento de la FNE (art. 20 inc. $2^{\circ}$ ).

42 Dentro de los casos donde se ha dado esta situación está la sentencia del Tribunal de la Libre Competencia, de 30 de septiembre de 2008. En este fallo se dio por establecidas una serie de conductas ilícitas en la aplicación de un sistema de cobro basado en un porcentaje de las ventas, en el caso de los terrenos e instalaciones subconcesionadas a las empresas courier. Así, el considerado 49a señala: "Que, en consecuencia, el régimen de cobros en base a kilogramos transportados a los subconcesionarios de servicios courier, configura un abuso de posición dominante ya que, al no poder implementar un sistema de cobros basado en el porcentaje de ventas de estas empresas, utilizó una variable que no estaba permitida en las Bases de Licitación, lo que permitió a SCL realizar un cobro mayor al que corresponde en caso de haber implementado la única alternativa factible, es decir, la de cobrar en base a los metros cuadrados facilitados, como se aprecia en el Cuadro siguiente (se ha excluido la información relativa a empresas couriers distintas de las demandantes de autos) (...)". Como consecuencia de lo anterior, el Tribunal de Defensa de la Libre Competencia, resolvió: 3. Acoger la demanda interpuesta en contra de SCL, en cuanto se declara que dicha empresa ha incurrido en las conductas de discriminación y abuso de posición dominante indicadas en esta sentencia (...). La CS, de 28 de enero de 2009 rechazó el recurso de reclamación (Rol No 6545-2008). 
En cambio, cuando es un tercero el que hace valer la sentencia en su beneficio, lo que se invoca es el efecto reflejo de la sentencia judicial.

Lo anterior se explica para este tercero por la forma como está configurado en nuestro sistema el ilícito contra la libre competencia en el DL 211. Como lo expone Menchaca, “(...) en materia de libre competencia la legislación nacional y gran parte de la extranjera han optado por tipificar las conductas contrarias a la libre competencia de manera general, a fin de permitir que las nuevas prácticas restrictivas que los agentes económicos vayan creando no queden impunes, logrando con ello una mayor eficacia de la norma, pero señalando, aunque de manera no taxativa, cuáles son las principales conductas sancionadas, a fin de dar un grado de razonable certeza jurídica a los agentes económicos (...)”43.

Pues bien, como el objeto del proceso discurre sobre una causal genérica, el pronunciamiento que el TDLC haga sobre la ilicitud o licitud de una conducta se identifica, necesariamente, con el conjunto de hechos que sirven de base para fundamentar el pronunciamiento acerca de la protección jurídica relativa al funcionamiento del mercado.

Ahora, si este tercero no participó en dicho proceso, ello no es un impedimento para que el fallo produzca en su beneficio una eficacia refleja, en cuanto le sirve de base para el ejercicio de la indemnización perseguida en el ulterior proceso.

Desde otro punto de vista, no reconocer al tercero la posibilidad de utilizar la sentencia del TDLC llevaría a que tenga que repetir el juicio fundado en los mismos hechos que ya fueron juzgados. En nuestra opinión, tal situación no se justifica, atendido que infringiría el principio del non bis in idem (no dos veces lo mismo). En efecto, si defiende que se debe iniciar por el tercero una nueva causa, se terminaría imponiendo más de una multa fundada en los mismos hechos.

Tema distinto es que el tercero deba acreditar las otras exigencias del ilícito civil cuya indemnización reclama, en especial, la relación de causalidad entre el hecho fijado en la sentencia como contrario a la libre competencia y el daño que demanda ${ }^{44}$.

Tampoco la circunstancia que un sujeto haya sido condenado por haber realizado prácticas atentatorias contra la libre competencia, prueba directamente el daño ocasionado a su contraparte en el proceso seguido ante el TDLC o a los terceros que invoquen en su beneficio la eficacia refleja de la sentencia. Lo anterior podría verse modificado si el fallo condenatorio consignó elementos fácticos que permitan, en el juicio posterior, hacer la inferencia que determina los perjuicios ocasionado a la parte o a terceros, por ejemplo, si se contienen las bases de cálculo u otros elementos de hecho que sirva para determinar el perjuicio por parte del juez civil competente.

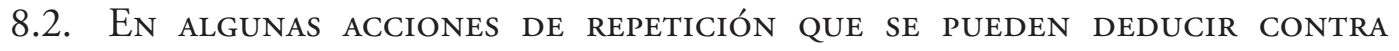 TERCEROS}

Otra manifestación de la sentencia como un hecho jurídico se puede dar con ocasión de acciones que se pueden deducir contra terceros, por haber operado algún supuesto previsto en la ley, que permite ejercer el derecho de repetición o de reintegro en su contra.

\footnotetext{
${ }^{43}$ Menchaca (2007) p. 38.

${ }^{44}$ Barros (2007) pp. 1042-1047. Sobre la relación de causalidad, Araya (2003) pp. 79-172.
} 
Aunque los preceptos son varios, recordemos a modo de ejemplo la situación que la acción de perjuicios que resulta de la evicción, cuando el citado no comparece y la cosa se pierde por sentencia judicial que quedó ejecutoriada (art. 1855 CC).

En el Código del Comercio también se contempla una situación similar en el art. 1249, cuando dispone que "la persona declarada responsable podrá ejercitar la acción de repetición que le corresponda, aun después de expirado dicho plazo de prescripción. Para ello, dispondrá de un plazo de seis meses, contado desde la fecha en que haya satisfecho voluntariamente la reclamación o haya sido condenado por sentencia firme a pagar en virtud de una acción ejercitada en su contra" ${ }^{45}$.

\section{LA EFICACIA "ULTRA PARTES" DE LA SENTENCIA}

La eficacia "ultra partes" se conecta con situaciones jurídicas donde hay varios sujetos legitimados o colegitimados, y cuya actuación puede producir que los efectos de una sentencia judicial se extiendan a terceros que se encuentran en su misma posición jurídica ${ }^{46}$.

Como se podrá apreciar, se trata de una excepción a la regla general, que sabemos limita los efectos de las sentencias a las partes, conforme a lo previsto en el art. $3^{\circ}$ in. $2^{\circ}$ del Código Civil ${ }^{47}$.

\subsection{La ACCIÓN DERIVATIVA DEL ART. 133 BIS DE LA LSA}

Una manifestación de sentencia "ultra partes" se recoge en la denominada acción derivativa, prevista en el artículo 133 bis a la LSA. Se trata de una hipótesis de legitimación extraordinaria, que permite a un accionista o un grupo de los mismos (con una participación a los menos el 5\% de las acciones emitidas) o también a un director, para demandar en nombre y beneficio de la sociedad, para el solo efecto de pedir una indemnización de perjuicios. El efecto normal de esta acción es la obtención de una restitución patrimonial para la sociedad, si prospera.

${ }^{45}$ En tal sentido, Hapag con Aria (2009).

46 Una exposición lata en CARPI (2007) pp. 15-125.

${ }^{47}$ En el último tiempo, reitera el contenido de esta regla Contreras con Banco de Chile (2007): “... De lo anterior se deriva el principio del efecto relativo del contrato o de la relatividad de su fuerza obligatoria o también llamado efecto directo de los contratos, que significa que aquellos solo generan derechos y obligaciones para las partes que concurren a su celebración, sin beneficiar ni perjudicar a los terceros, a quienes, por ende, no les empecen. Tal principio no es sino una representación, a su vez, del principio de la autonomía de la voluntad. Este efecto relativo asignado a los contratos no es exclusivo de ellos sino que también lo es a las sentencias. Así, al respecto, el Profesor René Abeliuk señala: "Es este un principio básico y fundamental del derecho y constituye un axioma jurídico indiscutible: "res inter alio acta, aliis neque nocere, neque prodesse potest" (que podríamos verter: las cosas hechas por unos, no perjudican ni aprovechan a los demás". Y agrega "No es tampoco un principio limitado a los contratos, ni siquiera a las convenciones, sino a todos los actos jurídicos y aún a ciertos actos de autoridad como son las sentencias $\left(\operatorname{art} 3{ }^{\circ}\right)$ : El efecto de cosa juzgada se refiere únicamente a las partes que han intervenido en el pleito. Solo la ley y otros actos de autoridad, expresamente autorizados por el ordenamiento jurídico: decreto, reglamento, etc., pueden ser de efectos generales. El efecto relativo del contrato consiste, pues, en que él afecta únicamente a las partes contratantes y no a aquellos que no han intervenido en su celebración” ("Las Obligaciones". Ediar Editores. Pág 114). De lo dicho resulta, en consecuencia, que la conciliación solo ha podido surtir efecto entre las partes que han concurrido a ella y, por lo mismo no puede haberlos producido y, por ende, afectar derechos y garantías constituidos a favor de terceros (...)”. 
Ahora, la ley no indica el alcance que tiene el efecto de cosa juzgada en el ejercicio de esta acción, pero la situación jurídica que resulta de esta sentencia invita a considerarla dentro del efecto "ultra partes". En efecto, no obstante que la sociedad anónima no es parte del juicio en que se deduce la acción derivativa, es ella la que en definitiva termina por beneficiarse de la sentencia, si los demandantes obtienen la indemnización de los perjuicios. Lo anterior significa que dicha sentencia es oponible a la sociedad y los otros sujetos legitimados para ejercer la acción derivativa ${ }^{48}$.

\subsection{EN MATERIA DE RESPONSABILIDAd CIVIL POR DAÑo AL MEDIO AMBIENTE}

Otra situación donde se contempla una hipótesis de varios colegitimados es en materia de responsabilidad civil por daño al medio ambiente. El art. 54 inc. $1^{\circ}$ de la Ley $\mathrm{N}^{\circ}$ 19.300, sobre Bases Generales del Medio Ambiente dispone que "son titulares de la acción ambiental señalada en el artículo anterior, y con el solo objeto de obtener la reparación del medio ambiente dañado, las personas naturales o jurídicas, públicas o privadas, que hayan sufrido el daño o perjuicio, las municipalidades, por los hechos acaecidos en sus respectivas comunas, y el Estado, por intermedio del Consejo de Defensa del Estado. Deducida demanda por alguno de los titulares señalados, no podrán interponerla los restantes, lo que no obsta a su derecho a intervenir como tercero. Para los efectos del artículo 23 del Código de Procedimiento Civil, se presume que las municipalidades y el Estado tienen interés actual en los resultados del juicio".

La eficacia "ultra partes" en este tema se da por el hecho que el legitimado que no demandó originalmente se verá alcanzado por la sentencia judicial, al ser titular del mismo derecho que es objeto de la discusión ${ }^{49}$.

\subsection{EN LA PROTECCIÓN A LOS CONSUMIDORES}

También en la regulación de la protección de los consumidores se da una hipótesis donde la eficacia de la sentencia puede alcanzar a terceros que, sin haber sido parte en un determinado proceso, puedan hacer valer en su beneficio un fallo judicial.

Esta situación se encuentra reconocida en la Ley $\mathrm{N}^{\circ} 19.496$ (reformada el 14 de julio de 2004 por la Ley No 19.955), a propósito del mecanismo de protección jurídica introducido en las acciones para tutelar el interés colectivo y difuso ${ }^{50}$.

\footnotetext{
${ }^{48}$ Romero y Díaz (2002) pp. 51-65.

${ }^{49}$ Si tiene interés en participar de este proceso lo podrá hacer mientras en juicio esté pendiente, y en calidad de interviniente litisconsorcial, ingresando al proceso como un auténtico litisconsorte que ejercita el derecho de acción. A nuestro entender, al calificar esta forma de intervención como adhesiva litisconsorcial se salva la restricción que la ley ha impuesto para el ejercicio de la acción a los otros afectados por el daño medioambiental. De la misma forma, esta calificación de la intervención guarda mayor coherencia con la propuesta de la doctrina científica que postula la existencia de un interés colectivo, que podría llevar a que varios sujetos, por ser portadores del mismo interés quieran participar en un único proceso para la reparación medioambiental. Sobre la forma de protección en este ámbito, Bordalí (2004) pp. 138-325. Sobre la naturaleza de este tercero, con una síntesis doctrinal, DÁvila (1997) pp. 35-37.

50 Sobre el tema, Aguirrezábal (2009) pp. 119-136; Aguirrezábal (2006) pp. 69-91; AguirrezÁbal (2006 b) pp. 21-39; Aguirrezábal (2006c) pp. 143-173.
} 
$\mathrm{El}$ art. 53 de la LPC, dispone que "una vez ejecutoriada la resolución que declaró admisible la acción, el tribunal ordenará al demandante que, dentro de décimo día, mediante publicación de al menos dos avisos en un medio de circulación nacional, informe a los consumidores que se consideren afectados, para que se hagan parte, si lo estiman procedente". Es mención esencial del aviso que confecciona el secretario del tribunal contener: "f) El llamado a los afectados por los mismos hechos a hacerse parte en el juicio, expresando que los resultados del juicio empecerán también a aquellos afectados que no se hicieran parte en él”.

Por su parte, el art. 54 de la LPC dispone que, "la sentencia ejecutoriada que declare la responsabilidad del o los demandados producirá efecto erga omnes, con excepción de aquellos procesos que no hayan podido acumularse conforme al número 2) del inciso final del art. 53, y de los casos en que se efectúe la reserva de derechos que admite el mismo artículo" 51 .

\subsection{EN MATERIA DE COMPETENCIA DESLEAL}

Otra manifestación de la eficacia "ultra partes" readmite en relación al ejercicio de la acción regulada para prevenir o sancionar la competencia desleal, en la Ley 20.169, de 2007.

En este caso existe una pluralidad de sujetos legitimados, que buscan un mismo fin. El art. 6 de esa ley, dispone que "cualquiera que resulte directa y personalmente amenazado o perjudicado en sus intereses legítimos por un acto de competencia desleal podrá ejercer las acciones señaladas en las letras a) a d) del artículo anterior”.

"Con todo, no habrá lugar a indemnización de perjuicios de acuerdo con esta ley si el demandado ya hubiese sido condenado a reparar el mismo daño de conformidad con otro ordenamiento legal".

"Las asociaciones gremiales que tengan por función efectiva la defensa de los intereses de agentes del mercado podrán interponer, en interés de sus miembros lesionados por un acto de competencia desleal, las acciones contempladas en las letras a) a c) del artículo anterior".

En nuestro medio ha postulado el alcance jurídico que analizamos Poblete, al reconocer que la sentencia que se dicta en este proceso se comporta como un hecho jurídico procesal frente a terceros ${ }^{52}$.

\section{LA SENTENCIA JUDICIAL COMO MEDIO DE PRUEBA EN LA PRODUCCIÓN DE PRECEDENTES}

\subsection{El Agravio QUe MOtiva LA NULIDAd}

Una especial proyección probatoria de la sentencia judicial se da en relación con la generación de los precedentes judiciales.

Esta realidad ha surgido en nuestra práctica forense a raíz del cambio introducido en el sistema de recursos con Ley $\mathrm{N}^{\circ}$ 19.374, de 18 de febrero de 1995. Allí se modificó radicalmente el funcionamiento de la Corte Suprema, organizándola en salas especializadas

\footnotetext{
51 Sobre el alcance de esta sentencia, Aguirrezabal (2010) pp. 99-124.

52 Poblete (2007) p. 130.
} 
y otorgando al Pleno la posibilidad de conocer el recurso de casación en el fondo para unificar la jurisprudencia contradictoria (art. 780 CPC). En la misma orientación, el Código Procesal Penal incorporó una causal de nulidad para que la Corte Suprema procediera, a instancia de parte, a unificar la doctrina jurisprudencial en el caso que existan distintas interpretaciones sostenidas en fallos diversos emanados de los tribunales superiores (arts. 376 inc. $2^{\circ}$ y 373 letra b) del CPP). Similar orientación ha seguido el nuevo proceso laboral. Para tal efecto, el art. 483 del Código del Trabajo dispone, "Procederá el recurso de unificación de jurisprudencia cuando respecto de la materia objeto del juicio existieren distintas interpretaciones sostenidas en uno o más fallos firmes emanados de Tribunales Superiores de Justicia" 53 .

La existencia de decisiones contradictorias en la jurisprudencia civil, penal o laboral, sobre un mismo tema configura actualmente un error decisorio litis, que surge cuando se resuelve un caso en forma diversa a una doctrina jurisprudencial.

Esta nueva regulación ha puesto de relieve una variante probatoria de la sentencia judicial, que no existía en la historia judicial chilena, atendido que para poder unificar la jurisprudencia se debe acreditar la existencia de una doctrina jurisprudencial, la que será objeto del pronunciamiento de unificación civil, penal o laboral.

\subsection{LA DISTINCIÓN ENTRE RATIO DECIDENDI Y OBITER DICTA}

Dentro de la actividad comparativa que precisa la técnica de generación y tratamiento de precedentes judiciales, una distinción importante es la diferencia entre ratio decidendi y obiter dicta. Aunque se trata de conceptos jurídicos de alcances poco pacíficos en la doctri$\mathrm{na}^{54}$, la utilidad de los mismos proviene del auxilio que otorgan a los jueces y a las partes para poder fijar qué parte de la sentencia contiene el precedente, esto es, la regla de origen judicial que por haberse dejado de aplicar en un caso análogo permite anular una decisión posterior.

En palabras de Gascón “( ) otro problema bien conocido de la técnica del precedente es el de la distinción entre ratio decidendi y obiter dicta, pues, dado que el precedente se obtiene no a partir de una cierta disposición normativa bien delimitada, sino de todo un conjunto de enunciados y argumentaciones que fundamentan una decisión, es preciso distinguir entre aquello que puede considerarse la razón básica de la decisión y aquellos otros pronunciamientos que la acompañan, por ejemplo, a título ilustrativo o no determinante; sin duda, solo aquella razón constituye o da lugar a un precedente, pero su delimitación no siempre resulta fácil ni clara" 55 .

Dicho de otra forma, que la decisión judicial decide en forma singular un caso anterior, no obsta a que la ratio decidendi de esa sentencia sirva de elemento constitutivo de un

\footnotetext{
53 Humeres y Halpern (2010) pp. 345-374; Juica (2009) pp. 33-44.

${ }^{54}$ Mayores antecedentes en López (2009) pp. 203-243.

${ }^{55}$ Gascón (1993) p. 46. Como lo expone Díez-Picazo, en un trabajo clásico sobre el valor de la jurisprudencia, “(...) entre estos razonamientos de índole jurídica que se vierten en los considerandos de una sentencias hay algunos que son la base y el fundamento inmediato de la decisión (ratio decidendi), pero hay otros que son puras afirmaciones incidentales, argumentos de orden retórico o dialéctico o manifestaciones que se hacen pura y simplemente a mayor abundamiento (obiter dicta). Pues bien: de una manera rigurosa, una sentencia del Tribunal Supremo consiste en lo que decide y en la razón inmediata de decidirlo en estrecha vinculación con el caso decidido. Solo esto es la verdadera jurisprudencia” Díez-PiCazo (1964) p. 933.
} 
agravio fundante de un recurso de nulidad. La Corte Suprema, considerando la ratio decidendi, contenida en una o varias sentencias anteriores, puede rescindir un fallo, por el solo hecho de haber prescindido los jueces del fondo de la doctrina jurisprudencial que debió ser considerada para resolver un conflicto actual entre partes.

\subsection{LA ACREDITACIÓN DE LA JURISPRUDENCIA QUE CONFIGURA EL AGRAVIO}

Una forma de cumplir con la acreditación de los dispares criterios de decisión que fundamentan la petición de nulidad, puede provenir de acompañar por la parte interesada las copias autorizadas de la o las sentencias anteriores.

Si no es posible cumplir con lo anterior, se podrá acompañar copias simples de las sentencias, incluyendo dentro de estas las que se obtengan de publicaciones en revistas o base de datos dedicadas a publicitar los fallos judiciales.

Esta segunda modalidad debe resultar tan eficaz como la primera, atendido que en relación a la unificación de la jurisprudencia lo que se busca es solo demostrar la existencia de decisiones jurisprudenciales contradictorias. En efecto, las sentencias aportadas con ese fin no son agregadas con la finalidad que tiene la producción de la prueba documental en un juicio, especialmente si se tata de un instrumento privado ${ }^{56}$.

Como lo explica Taruffo, "el uso como pruebas y el valor probatorio de los documentos se basa en la suposición de que estos son auténticos. Es obvio que solo cuando un documento tiene estos requisitos puede utilizarse como medio de prueba de un hecho o de una transacción jurídica. Por ello el problema es garantizar y verificar la autenticidad y fiabilidad de los documentos escritos" 57 . Ahora, como en esta proyección probatoria solo se busca acreditar la existencia de una doctrina jurisprudencial para efectos de unificarla, tal objetivo se debe entender cumplida si la que se aporta a la causa es fiable.

Es lógico pensar que por la dialéctica propia del sistema de generación de precedentes, será la contraparte la primera en denunciar una irregularidad cuando su contraria alega la existencia de una doctrina que no existe, ya sea porque falsificó ideológica o materialmente las sentencias. La misma comprobación la puede hacer la Corte Suprema, cuando tiene dudas acerca de la existencia del precedente materia de la disputa. Esta tarea que se ve

\footnotetext{
56 Esta exigencia se aplica como un medio de control de la prueba que consta en instrumentos privados. En tal sentido se ha resuelto que a) “...si un documento no emana de la parte contra quien se hace valer no puede producir el valor probatorio que establece el artículo 1702 del Código Civil”. Fuentes con Poitzick (1977). b) "El documento privado se caracteriza, sustancialmente, por no estar protegido por la fe pública que se debe a los instrumentos públicos y que proviene de la participación de un funcionario público en su formulación, cumpliendo formalidades especiales. De tal manera, el instrumento privado solo hace prueba cuando ha sido reconocido dentro del juicio y el que no lo ha sido, carece de todo mérito, incluso como base de presunción judicial" (Vanni con Ortiz (1981). c) "Procede acoger la objeción que una de las partes formule respecto de documentos que emanan de empleados de la otra, consistentes en tarjetas de contabilidad, puesto que no es posible que la propia parte de quien emanan los haga valer en apoyo de sus pretensiones"... (Empresa con Industria (1984); d) "Un documento privado emanado de un tercero no es sino una prueba testifical rendida sin las formalidades legales y consiguiente nula y carente de mérito de prueba, incluso como base de una presunción judicial". // "El hecho que a un documento privado se adicione una certificación notarial, no lo convierte en público así como tampoco podría variar la calidad de este último por anotarse en él una mención que solo signifique la dación de un instrumento privado". Iglesias con Cabargas (1990).

57 TARUfFo (2008) p. 81.
} 
facilitada en el último tiempo por el desarrollo de su base de datos, que le permitirle acceder a las sentencias pronunciadas por los distintos jueces y tribunales el país.

Debe estimarse que junto a las copias autorizadas (que siempre tendrán la calidad de documentos auténticos), también es factible estimar como fiables las copias simples no autorizadas de los fallos judiciales, las decisiones publicadas en revistas especializadas, libros de recopilación o incluso, las que están incorporadas a bases de datos ${ }^{58}$.

Dicho de otra forma, se debe reconocer que para estos efectos la sentencia judicial tiene un rol diverso del que es exigible al documento cuya función es servir de requisito de validez de un acto jurídico (ad solemnitatem), o como un medio de prueba que sirva para resolver una controversia entre partes (ad probationem). En efecto, la declaración del derecho contenida en una sentencia firme paradójicamente cumple una función probatoria en lo que pacíficamente se entiende que no hay que rendir prueba: en relación al derecho. En el mecanismo de generación de precedentes las sentencias se aportan justamente para comprobar como ha sido aplicado el derecho en casos singulares, pero de cuya solución ha surgido una pauta de decisión que queda vinculada a la disputa judicial que surge entre partes a propósito de un recurso de unificación jurisprudencial.

A modo de simple referencia, ilustra la flexibilidad que se reclama para esta proyección probatoria de la sentencia judicial lo manifestado, hace más de un siglo, en la nota de presentación del primer número de la Revista de Derecho y Jurisprudencia, el 30 de noviembre de 1903. Allí se expresaba: "el establecimiento en Chile del recurso de Casación, como medio de corregir las infracciones de la ley en el fallo de las contiendas judiciales, no produciría todos sus efectos si no llegara á uniformarse la jurisprudencia por medio de la adopción en cada caso análogo de la doctrina jurídica sentada por la Corte Suprema”. "La Corte de Casación, dicen los redactores de las Pandectas Francesas, tiene por misión mantener la unidad de la jurisprudencia y asegurar el respeto á la ley y su aplicación estricta". "Para fundar la unidad de la jurisprudencia es indispensable que las resoluciones de la Corte Suprema alcancen toda la publicidad necesaria a fin de que se llegue al conocimiento no solo de los que tienen que aplicar las leyes, sino también de todos aquellos que auxilian ó dirigen la acción de los litigantes y de estos mismos". "Procurar esta publicidad en una forma metódica y ordenada y de fácil consulta, es el primer objeto de la Revista de Derecho y Jurisprudencia"59.

Por todo lo anterior, resulta criticable las restricciones que se han ido imponiendo en la admisibilidad de los recursos que buscan unificar la jurisprudencia, cuando ellos son desestimados por no haberse agregado materialmente las sentencias en copia autorizada ${ }^{60}$. Al restringir la aportación de las sentencias a las que se encuentren autentificadas por un ministros de fe, se está imponiendo una auténtica probatio diabolica, que muy pocos podrán sortear, ya sea por imposibilidad física o económica. Al mismo tiempo, esa forma de proceder limita en desarrollo del derecho de precedentes que, desde 1995, ya está instalado en el sistema de impugnación del proceso civil, penal y laboral.

\footnotetext{
${ }^{58}$ Sobre esta temática, Elí́As (2008) pp.19-42.

${ }^{59}$ Una síntesis histórica del origen de esta publicación, Libedinsky (2002) p. 42.

${ }^{60}$ Cortés (2006) pp. 101-104 y 128-131; Rieutord (2009) pp. 83-84.
} 


\section{BIBLIOGRAFÍA}

Aguirrezábal Grünstein, Maite (2009): “Capacidad para ser parte y capacidad de los grupos de consumidores afectados: su tratamiento en la ley de protección de consumidores y en el anteproyecto del Código Procesal Civil" en La reforma Procesal Civil en Chile, (VV.AA.), U. de los Andes, Cuadernos de Extensión No 16, 2009, pp. 119-136.

Aguirrezábal Grünstein, Maite (2006): "Algunas precisiones en torno a los intereses supraindividuales (colectivos y difusos)", en Revista Chilena de Derecho, volumen 2006, $\mathrm{n}^{\circ}$ 1, pp. 69-91.

AguirrezÁbal Grünstein, Maite (2006): "La Legitimación de las asociaciones de consumidores y usuarios en la nueva Ley de Enjuiciamiento Civil”, en Revista Vasca de Derecho Procesal y Arbitraje (España), 2006, tomo XVIII, pp. 21-39.

AguirrezÁbal Grünstein, Maite (2006): "El procedimiento para la defensa de intereses colectivos y difusos de consumidores y usuarios en la Ley 19.946”, Cuadernos de Extensión Jurídica, Universidad de los Andes, 2006, pp. 143-173.

AguirrezÁbal Grünstein, Maite (2010): "La extensión de los efectos de la sentencia dictada en procesos promovidos para la defensa de los intereses colectivos y difusos de los consumidores y usuarios: régimen en la ley chilena de protección al consumidor”, en Ius et Praxis, $\mathrm{N}^{\circ}$ 1, 2010, pp. 99-124.

Araya Jasma, Fernando (2003): La relación de causalidad en la responsabilidad civil (Santiago: LexisNexis) 220 pp.

Ballesteros, Manuel E. (1890): La Lei de Organización i Atribuciones de los Tribunales de Chile (Santiago, Imprenta Nacional) t. II, 847 pp.

Barros Bourie, Enrique (2007): Tratado de responsabilidad extracontractual (Santiago: Editorial Jurídica de Chile) 2007 reimp., 1230 pp.

Bordalí Salamanca, Andrés (2004): Tutela Jurisdiccional del Medio Ambiente (Santiago: Fallos del Mes) $485 \mathrm{pp}$.

Calamandrei, Piero (1986): "Verdad y verosimilitud en el proceso civil", en Estudios sobre el proceso civil, t. III, Tr. S. Sentis Melendo (B. Aires: EJEA) 531 pp.

Carpi, Federico (2007): La eficacia "ultra partes" de la sentencia civil (Lima: La Palestra, tr. J.J. Monroy Palacios) 568 pp.

Carreras Llansana, Jorge (1962): "Naturaleza jurídica y tratamiento de las presunciones", en Estudios de Derecho Procesal (Con FENECH), Barcelona: Bosch, 1962, 802 pp.

Claro Solar, Luis (1898): Explicaciones de derecho civil chileno y comparado (Santiago: Establecimiento Poligráfico Roma) t. I, 529 pp.

Comoglio, Luigi P. (2004): Le prove civili (Turín: UTET) 729 pp.

Cortés Matcovich, Gonzalo (2006): El recurso de nulidad (Santiago: LexisNexis) 440 pp.

DÁvila Millán, María Encarnación (1997): El litisconsorcio necesario (Barcelona: Bosch, $3^{a}$ ed.) $258 \mathrm{pp}$.

Devis Echandia, Hernando (2002): Teoría general de la prueba judicial, Teoría general de la prueba judicial (Bogotá: Temis) t. II, 1475 pp.

Díaz Villalobos, José Ignacio, Romero Seguel, Alejandro, "La acción de responsabilidad civil del art. 133 bis de la Ley de Sociedades Anónimas, RDJ, T. XCIX, pp. 51-65. 
Díez-Picazo, Luis (1964): "Reflexiones sobre la jurisprudencia del Tribunal Supremo (la jurisprudencia en broma y en serio)" en Revista de Derecho Privado, Madrid, nov., 1964, p. 933.

Elías Baturones, Julio (2008): La prueba de documentos electrónicos en los tribunales de justicia (Valencia: Tirant lo Blanch) 174 pp.

Gascón Abellán, Marina (2004): Los hechos en el derecho (Madrid; Marcial Pons, 2a ed.) $230 \mathrm{pp}$.

Gascón Abellán, Marina (1993): La técnica del precedente y la argumentación racional (Madrid: Tecnos) $230 \mathrm{pp}$.

Grande Seara, Pablo (2008): La extensión subjetiva de la cosa juzgada en el proceso civil (Valencia: Tirant) 499 pp.

Humeres Noguer, Héctor (con Halpern Montecino, Cecily) (2010): "La intervención de la Corte Suprema en la nueva justicia del trabajo: el recurso de unificación de la jurisprudencia”, en Actualidad Jurídica, N²1, 2010, pp. 345-374.

Juica Arancibia, Milton (2009): "Los recursos procesales en el nuevo procesal laboral” (Colegio de Abogados) pp. 33-44.

Libedinsky Tschorne, Marcos (2002): "Revista de Derecho y Jurisprudencia”, en Revista del Abogado, No 25, julio 2002, p. 42.

Liebman, Enrico (1946): Eficacia y autoridad de la sentencia (Buenos Aires: Ediar (tr. Sentís Melendo)) $287 \mathrm{pp}$.

Lira, José Bernardo (1895): Prontuario de los juicios o tratados de procedimientos judiciales $i$ administrativos con arreglo a la legislación chilena (Santiago, Mariano Servat) t. I, 468 pp.

López Medina (2009): El Derecho de los Jueces (Bogotá: Legis, 8ª reimp.) 220 pp.

Martínez de Aguirre, Carlos (2004): “Robert Joseph Pothier”, en Juristas Universales, (Domingo, Rafael, editor) (Marcial Pons) t. II p. 582.

Martínez de Morentín Llamas, María Lourdes (2007): Régimen jurídico de las presunciones (Madrid: Dykinson) 203 pp.

Menchaca Olivares, Tomás (2007): "Libre competencia y competencia desleal en la Ley 20.169, ¿Existe contradicción entre ambas disciplinas?, en Competencia Desleal, Facultad de Derecho Universidad de los Andes, CEJ N 14, 2007, p. 38.

MendoçA, Daniel (2003): "Estudio preliminar" en el libro Ficciones Jurídicas (Hans Kelsen. Lon F. Fuller. Alf Ross) (México: Fontamara) 124 pp.

Meneses Pacheco, Claudio (2008): "Fuentes y medios de prueba en el proceso civil", Ius et Praxis, No 2, 2008, pp. 43-86.

Moreno Navarrete, Miguel (2001): La prueba documental (Madrid: Marcial Pons) 437 pp.

Nieva Fenoll, Jordi (2006): La cosa juzgada (Barcelona: Atelier) 309 pp.

Poblete Iturriate, Orlando (2007): "El proceso civil de competencia desleal" en Cuadernos de Extensión Jurídica No 14, 2007 p. 130.

Picó I Junoy, Joan (1996): El derecho a la prueba en el proceso civil (Barcelona: J.M. Bosch) 446 pp.

Rieutord Alvarado, Andrés (2009): El recurso de nulidad en el nuevo proceso penal (Santiago: Editorial Jurídica de Chile, reip. $1^{a}$ ed.) 257 pp.

Romero Seguel, Alejandro, Díaz Villalobos, José Ignacio: "La acción de responsabilidad civil del art. 133 bis de la Ley de Sociedades Anónimas, RDJ, T. XCIX, pp. 51-65. 
Rosende Villar, Cecilia (2001): “Efectos directos y reflejos de la sentencia”, en Revista Chilena de Derecho, vol. 28 No 3, 2001, pp. 493-494.

TAPia Fernández, Isabel (2000): El objeto del proceso. Alegaciones. Sentencia. Cosa juzgada (Madrid, La Ley) 239 pp.

TAPIA Fernández, Isabel (2010): La Cosa Juzgada (Madrid: Dykinson) 270 pp.

TAvolari Oliveros, Raúl (2000): "Límites objetivos de la cosa juzgada civil (intento de delimitar la cuestión en el derecho chileno)", en El proceso en acción (Editorial Libromar) 712 pp.

Taruffo, Michele (2008): La prueba (Madrid: Marcial Pons) (Traducc. L. Manríquez y J. FERrer) $324 \mathrm{pp}$.

Wach, Adolf (1997): Manual de Derecho Procesal Civil (tr. Banzhaf), T. I, (Ediciones Jurídicas Europa-América, Buenos Aires) 585 pp.

\section{NORMAS CITADAS}

Código Civil: art. $3^{\circ}$ in. $2^{\circ}$.

Código de Procedimiento Civil: arts. 23, 83, 84, 85, 429, 780.

Código Procesal Penal: arts. 376 inc. $2^{\circ}$ y 373 letra b).

Código del Trabajo: art. 483.

Código Orgánico de Tribunales: art. 545.

Código de Comercio: art. 1249.

Ley 20.169, de 2007, sobre competencia desleal.

Ley $\mathrm{N}^{\circ} 19.496$ sobre protección a los derechos de los consumidores (reformada el 14 de julio de 2004 por la Ley No 19.955).

Ley $\mathrm{N}^{\circ} 19.300$, sobre Bases Generales del Medio Ambiente.

Ley $\mathrm{N}^{\circ} 19.374$, de 18 de febrero de 1995, sobre funcionamiento de la Corte Suprema.

DL 211 de 1973 (modificado por la Ley No 20.361 de 13 de julio de 2009).

\section{JURISPRUDENCIA CITADA}

Aceituno, Olga con Aceituno, Fernando (2010): Corte Suprema, 1 de junio de 2010, Rol 4983-08, MJ 24086.

Anrique, Teresa con Monasterio de la Buena Enseñanza (1921): Corte Suprema, 6 de octubre de 1921, Gaceta, 1921, $2^{\circ}$ sem., No 64, p. 262.

Banco del Estado de Chile con Lincir, Pablo (1992): Corte Suprema, 31 de agosto de 1992, RDJ, t. 89, sec. $1^{\text {a }}$, p. 136.

Banco Hipotecario con Lagos (1924): Corte Suprema, 30 de julio de 1924, RDJ, t. 22, sec. $1^{\mathrm{a}}$, p. 1037.

Bauzá con Dirección de Impuestos Internos (1939): Corte Suprema, 12 de enero de 1939, RDJ, t. 36, sec. $1^{\text {a }}$, p. 466.

Benacchio, Marcos, R. de Queja (1951): Corte Suprema, 29 de mayo de 1951, RDJ, t. 48, sec. $1^{\text {a }}$ p. 139.

Castro Figueroa, Ángel con Garretón, Óscar (1981): Corte Suprema, 7 de julio de 1981, RDJ, t. 78 , sec. $1^{\text {a }}$, p. 138. 
Contreras Jara, María con Banco de Chile y otros (2008): Corte Suprema, 28 enero de 2008, Rol 110- 06, MJ 16441.

Desafuero Augusto Pinochet U. (2002) Corte de Apelaciones de Santiago 7 de octubre de 2002. Rol No 46.071-2002.

Empresa Nacional de Comercialización con Industria Valmoval Ltda. (1984): Corte de Apelaciones Pedro Aguirre Cerda, 30 de julio de 1984, RDJ, t. 81, sec. 2a , p. 100.

Fedex y otros con con SCL (2009): Corte Suprema, 28 de enero de 2009 (Rol No 6545-2008).

Fuentes, Francisco con Poitzick, Alfredo (1977): Corte Suprema, 19 de octubre de 1977, RDJ, t. LXXIV, sec., 1a, p. 142.

Hapag Lloyd con Aria Textil Ltda (2009): Corte de Apelaciones de Santiago, 3 de noviembre de 2009, Rol 5355-08, MJ 23594.

Iglesias Gonzalez, Rodrigo con Cabargas, Jorge (1990): Corte Apelaciones Santiago, 16 de agosto de 1990, RDJ, t. 87, sec. $2^{\mathrm{a}}$, pp. 158-163.

Industrias Publicitarias Nacional con Impuestos Internos (1972): Corte Suprema, 15 de mayo de 1972, RDJ, t. 69, sec. $1^{\text {a }}$, p. 59.

Japaz Lulo, Moris con Balbontín Pérez, Rafael (1980): Corte Suprema, 23 de junio de 1980, RDJ, t. 77 , sec. $1^{\text {a }}$, p. 49.

Macuada con Macuada y otra (1939): Corte Suprema, 24 de agosto de 1939, RDJ, t. 37, sec. $1^{\text {a }}$, p. 229.

Marchant con Gobierno de China Nacionalista (1969): Corte Suprema, 3 de septiembre de 1969, RDJ, t. LXVI, sec. 3a, pp. 125-130.

Moya, María con Rojas, Juan (2010): Corte Suprema, 5 de abril de 2010, Rol No 7415, MJ2358.

Municipalidad de San Fernando con Espinoza y otros (2000): Corte Suprema, 29 de agosto de 2000, MJ 3184.

O'Ryan, Julio con Ruiz Tagle, Olga (1970): Corte Suprema, 24 de junio de 1970, RDJ, t. 67, sec. $1^{\text {a }}$, p. 219.

Phillips, Hernán y otra con Baeza, Francisco (1994): Corte Suprema, 4 de octubre de 1994, RDJ, t. 91, p. 88.

Senerman con República de Cuba (1975): Corte Suprema, CS, 2 de mayo de 1975, F. del M. $\mathrm{N}^{\circ} 199$, pp. 90-93.

Sociedad Contractual Minera Carola con Sociedad Punta del Cobre S.A. (2002): Corte Suprema, 6 de mayo de 2002, RDJ t. XCIX, sec. 1a , p. 78.

Schweitzer. R. de Inaplicabilidad (1932): Corte Suprema, 10 de octubre de 1932, RDJ, t. 30 , sec. $1^{\mathrm{a}}$, p. 76.

Undurraga, José con Ugarte de la Plaza, Carlos (1956): Corte Suprema, 23 de julio de 1956, RDJ, t. 53, sec. $1^{\text {a }}$, p. 143.

Vanni, Laura con Ortiz, Humberto (1981): Corte de Apelaciones de Santiago, 26 de mayo de 1981, RDJ, t. 78, sec. 2a, p. 69.

Vásquez, Wilson con Vásquez Aurelio y otros (1965): Corte de Apelaciones de Temuco, 23 de septiembre de 1965, RDJ, t. 63, sec. 2a, p. 137.

Zañartu vda. De Urrutia con Higueras vda. de Quiroz (1937): Corte Suprema, 1 de junio de 1937, RDJ, t. 34 , sec. $1^{\text {a }}$, pp. $277-290$. 